\title{
Pharmacologic Studies on the Dibutyl and $\gamma$-Monobutyl Esters of Methotrexate in the Rhesus Monkey
}

\author{
Andre Rosowsky, Herbert T. Abelson, G. Peter Beardsley, William D. Ensminger*, Donald W. Kufe, \\ Glenn Steele, and Edward J. Modest** \\ Sidney Farber Cancer Institute and Harvard Medical School, 44 Binney Street, Boston, MA 02115, USA
}

\begin{abstract}
Summary. The pharmacokinetics and metabolism of dibutyl methotrexate (DBMTX) and $\gamma$-monobutyl methotrexate $(\gamma-M B M T X)$ were studied in Rhesus monkeys. When a bolus IV dose of either $\left[{ }^{3} H\right] D B M T X$ or $\left[{ }^{3} H / \gamma-M B M T X\right.$ was given, the principal species in serum for up to $1 \mathrm{~h}$ was the monoester, with $M T X$ accounting for $<10 \%$ of the total radioactivity. Products other than $\gamma-M B M T X$ and MTX were formed in substantial amounts with DBMTX, but not with $\gamma-M B M T X$. Total radioactivity recovered in the bile $5 \mathrm{~h}$ after $\left[{ }^{3} \mathrm{H} \mid D B M T X\right.$ injection accounted for $32 \%$ of the administered dose, indicating high hepatic extraction for this lipophilic compound. Serum and CSF levels of unchanged $\gamma-M B M T X$, as well as of $M T X$ arising via esterase cleavage, were measured by HPLC after IV infusion of $\gamma$-MBMTX $\left(10 \mathrm{~g} / \mathrm{m}^{2}\right)$. Efflux of monoester from CSF was slower than disappearance from serum. However, $\gamma-M B M T X$ levels in CSF were no higher than could be attained by infusing $M T X$ itself at the same dose rate. While CSF/serum ratios were ca. 10-fold higher for $\gamma-M B M T X$ than for $M T X$, this difference could be explained on the basis of the very different affinities of the two compounds for serum proteins. HPLC analysis of serum processed by methanol precipitation as opposed to ultrafiltration of the proteins showed $\gamma-M B M T X$ to be $>99 \%$ bound, whereas for MTX this value was $50 \%$ or less. When $\gamma-M B M T X$ and MTX levels measured after ultrafiltration were corrected for this difference in serum protein binding the total amount of the two drugs in serum became almost equivalent.
\end{abstract}

\section{Introduction}

Diesters and monoesters of MTX have been studied actively in this laboratory $[2,8,20,22,25,26]$ and others $[10,13,14]$ for a number of years. Interest in these compounds arose from the idea that decreasing the polar character of the glutamate side-chain in MTX might give rise to favorable changes in biological activity $[6,7]$. Esterification of the glutamate

Reprint requests should be addressed to A. Rosowsky

* Present address: Department of Internal Medicine, University of Michigan School of Medicine. Ann Arbor, MI 48109, USA

** Present address: Department of Biochemistry, Bowman Gray

Medical School, Winston-Salem, NC 27103, USA

The abbreviations used are: MTX, methotrexate (4-amino-4-deoxy- $N^{10}$-methylpteroyl-L-glutamic acid); DBMTX, dibutyl methotrexate (NSC-305985); $\gamma$-MBMTX $=\gamma$-monobutyl methotrexate (NSC-305986); DDMP 2,4-diamino-5-(3'.4'-dichlorophenyl)-6-methylpyrimidine (NSC-19494); CSF, cerebrospinal fluid; HPLC, high-performance liquid chromatography; TLC, thin-layer chromatography carboxyl groups is one structural modification that can be made to achieve this end. Other approaches include the formation of amide and peptide derivatives [18, 21, 23, 29]. The absence of free carboxyl groups in these MTX analogues was expected to lessen dependence on the carrier-mediated transport pathway for drug uptake by promoting passive diffusion through the cell membrane [25]. The lipophilicity of the carboxyl-blocked derivatives might cause them to have advantageous tissue distribution properties, such as improved percutaneous absorption $[17,32]$ and the ability to penetrate pharmacologic sanctuaries such as the CSF, whose permeability to MTX is low $[27,28]$.

Although MTX diesters prolong the life of mice with L1210 leukemia, this has been ascribed to rapid in vivo hydrolysis to MTX $[10,13,14,20]$. Since the diesters inhibit dihydrofolate reductase less effectively than MTX by as much as two orders of magnitude, direct antitumor action by these compounds in the murine L1210 system was judged to be unimportant. Other studies, however, suggested that MTX diesters do not behave identically with MTX and may therefore deserve consideration as antitumor agents in their own right. Unlike MTX, the dibutyl ester DBMTX blocks $\left[{ }^{3} \mathrm{H}\right]$ thymidine incorporation into the DNA of $\mathrm{L} 1210$ cells in serum-free culture for up to $2 \mathrm{~h} \mathrm{[8]}$. This was found to be due to an unexpected inhibitory effect on uptake of the nucleoside across the cell membrane rather than to inhibition of kinase or DNA polymerase activities, and was shown not to be confined to a single pyrimidine nucleoside or a single cell type [2].

Significant differences between DBMTX and MTX were noted also in experiments utilizing MTX-sensitive and MTX-resistant human leukemic lymphoblasts (CEM cells) in culture [25]. A stable line which is 120 -fold resistant to MTX and owes its resistance to decreased MTX uptake rather than to elevated dihydrofolate reductase activity was found not to be cross-resistant to either DBMTX or other lipid-soluble nonclassic antifolates such as DDMP. DBMTX was also found to be more effective than MTX in blocking $\left[{ }^{3} \mathrm{H}\right]$ deoxyuridine incorporation in MTX-resistant CEM cells [25], as well as MTX-resistant L1210 cells [8]. These findings provided experimental support for the concept that transport resistance to classical antifolates may be overcome by blocking the carboxyl groups in the glutamate side-chain so as to promote uptake by passive diffusion. The term 'hybrid antifolate' was coined to describe compounds such as DBMTX, whose overall structure retains most of the features of classical antifolates but whose uptake is more likely to resemble that of antifolates of the lipid-soluble, nonclassical type [25]. 
A significant aspect of the pharmacology of MTX esters has been the discovery that their cleavage by serum esterases is species-dependent [24]. Thus, whereas mouse or rat serum converts DBMTX almost entirely to MTX after $24 \mathrm{~h}$ at $37^{\circ} \mathrm{C}$ in vitro, human or monkey serum under identical conditions leaves most of the diester unchanged, with some conversion to the $\gamma$-monobutyl ester ( $\gamma$-MBMTX) along with small quantities of the $\alpha$-isomer ( $\alpha$-MBMTX) and some free MTX. The $\gamma$-monoester, $\gamma$-MBMTX, is much more active than DBMTX against dihydrofolate reductase in vitro, with an $\mathrm{ID}_{50}$ value approaching that of MTX itself [24].

In this paper we report the results of experiments on the in vivo pharmacokinetics and metabolic fate of the diester DBMTX and monoester $\gamma$-MBMTX in Rhesus monkeys. The results show that despite its relative stability in serum in vitro, DBMTX is rapidly metabolized in vivo, and that significant amounts of products other than $\gamma$-MBMTX and MTX are formed. In contrast, the monoester $\gamma$-MBMTX is relatively stable, and gives essentially no metabolites other than MTX. Apart from a markedly greater affinity of $\gamma$-MBMTX for serum proteins, no major pharmacologic differences between $\gamma$-MBMTX and MTX were observed.

\section{Materials and Methods}

Animals. Adult Rhesus monkeys (Macaca mulatta) weighing $10-15 \mathrm{~kg}$ were housed in individual cages and fed standard laboratory chow. Surface areas were calculated by means of the formula: Area $\left(\mathrm{m}^{2}\right)=\left(1.18 \times 10^{-3}\right)$ [body weight $\left.(\mathrm{g})\right]^{2 / 3}$ [19]. To facilitate CSF sampling, cisternal catheters and subcutaneous Ommaya reservoirs were implanted surgically in three of the animals. Alternatively, CSF was obtained by lumbar puncture. One monkey had an indwelling biliary diversion tube which was exposed surgically during the experiment to permit bile collection via a 21 -gauge needle inserted into the tube. Urine was obtained via a pediatric ureteral catheter, or in some instances by means of a suprapubic bladder tap. Blood sampling was done either through a femoral vein catheter or by simple venipuncture. Animals were anesthetized with phenycyclidine hydrochloride or ketamine [19], with phenobarbital or thiamylal added as needed for preliminary sedation. Intravenous fluids (5\% glucose in $0.9 \%$ sodium chloride) were administered at $0.5-2.0 \mathrm{ml} / \mathrm{min}$.

Animals receiving high doses $\left(10 \mathrm{~g} / \mathrm{m}^{2}\right)$ of $\gamma$-MBMTX or MTX were given $150 \mathrm{mg}$ leucovorin $/ \mathrm{kg}$ daily in divided doses for at least 4 days, starting $24 \mathrm{~h}$ after drug infusion. Blood for HPLC analysis of the 24-h drug levels was drawn prior to the leucovorin injection so that the latter would not affect the pharmacokinetics. Whenever the same animal was used more than once, at least 3 months were allowed between experiments to ensure complete recovery. Serum creatinine levels, hepatic function tests, and peripheral blood counts were established to be within normal limits for Rhesus monkeys before each experiment.

Drugs. $\left[{ }^{3} \mathrm{H}\right]$ DBMTX was synthesized as previously described [8], and purified by column chromatography on silica gel (Baker 3405, 60-200 mesh) with $95: 5 \mathrm{CHCl}_{3}-\mathrm{MeOH}$ as the eluent. This method was extremely effective in removing any unreacted or incompletely esterified MTX, as well as other products resulting from esterification of contaminants in the starting material. The chemical homogeneity of the product was established by TLC analysis on silica gel (Eastman 6060 , with fluorescent indicator) using $4: 1 \mathrm{CHCl}_{3}-\mathrm{MeOH}$ as the eluent. The $R_{f}$ value, 0.8 , was in agreement with earlier findings [20]. The radiochemical purity of the product was established by scraping zones from the TLC plate and analyzing them by scintillation counting. At least $95 \%$ of the radioactivity was contained in the spot co-migrating with an authentic sample of pure DBMTX.

For the preparation of $\left[{ }^{3} \mathrm{H}\right] \gamma$-MBMTX, the following modification of the cesium carbonate technique used earlier [22] was employed. Unlabeled MTX free acid (100 mg, 0.22 $\mathrm{mmol}$ ) and cesium carbonate $(71.7 \mathrm{mg}, 0.23 \mathrm{mmol})$ were added to a solution of $\left[{ }^{3} \mathrm{H}\right] \mathrm{MTX}$ disodium salt $(5 \mathrm{mCi})$ in $4 \mathrm{ml}$ dimethylsulfoxide. The radiolabeled starting material (sp. act. 5-20 Ci/mmol) was used directly as supplied by Moravek Biochemicals, City of Industry, CA, USA, or by the National Cancer Institute, Bethesda, MD. After $1 \mathrm{~h}$ at room temperature, 1-bromobutane $(35.3 \mathrm{mg}, 0.23 \mathrm{mmol})$ was added and stirring was continued for another $40 \mathrm{~h}$. The reaction mixture was then freeze-dried, the solid residue triturated with water, the $\mathrm{pH}$ adjusted to 4.0 with $1 \mathrm{~N} \mathrm{HCl}$, and the undissolved material filtered, washed with ice-cold water, and dried in vacuo over phosphorus pentoxide. This product $(102 \mathrm{mg})$ was purified by dry-column chromatography on silica gel (Woelm activity grade III/30 mm, ICN Pharmaceuticals, Cleveland, $\mathrm{OH}$, USA) as described previously [24]. The column was eluted successively with $500-\mathrm{ml}$ portions of $95: 5,90: 10$, $85: 15,80: 20$, and $70: 30 \mathrm{CHCl}_{3}-\mathrm{MeOH}$. Individual $9-\mathrm{ml}$ fractions were monitored by TLC (Analabs silica gel OF, $3: 1$ $\mathrm{CHCl}_{3}-\mathrm{MeOH}$ ), and appropriate fractions were pooled and evaporated to obtain [ $\left.{ }^{3} \mathrm{H}\right] \mathrm{DBMTX}$ (tubes $7-20,26 \mathrm{mg}, 21 \%$ yield), $\left[{ }^{3} \mathrm{H}\right] \alpha$-MBMTX (tubes $109-150,14 \mathrm{mg}, 13 \%$ yield), and $\left[{ }^{3} \mathrm{H}\right] \gamma$-MBMTX (tubes $161-230,28 \mathrm{mg}, 25 \%$ yield). Each product was radiochemically pure by TLC analysis and scintillation counting of zones scraped from the TLC plate. The specific activity of $\left[{ }^{3} \mathrm{H}\right] \gamma$-MBMTX after passage through the silica gel dry column was determined to be $16 \mathrm{mCi} / \mathrm{mmol}$ by scintillation counting of a precisely weighed amount. Immediately prior to use, the labeled monoester was dissolved in dilute $\mathrm{NaOH}$ or $0.05 M$ Tris buffer, $\mathrm{pH} 8.0$.

Nonradioactive $\gamma$-MBMTX for the high-dose experiments was generously provided by Dr Robert Angier, Lederle Laboratories, Pearl River, NY, USA. The synthesis of the monoester by partial saponification of DBMTX and preparative HPLC purification has been described [30]. For a high-dose infusion experiment, a typical procedure for preparing the infusate consisted of adding $4.83 \mathrm{~g} \gamma$-MBMTX free acid, in small portions with rapid stirring, to $175 \mathrm{ml}$ water containing enough $10 \mathrm{~N} \mathrm{NaOH}$ to bring the $\mathrm{pH}$ to 9.0. The solution was kept at $0^{\circ} \mathrm{C}$, and the $\mathrm{pH}$ was monitored continuously with the aid of a meter. When addition of the monoester was complete a few drops of $1 \mathrm{~N} \mathrm{HCl}$ were added to bring the final $\mathrm{pH}$ to $8.5-8.7$. This freshly prepared solution was sterile-filtered through a $0.45-\mu \mathrm{m}$ membrane disc (Amicon Corp., Bedford, MA, USA) connected to a disposable $100-\mathrm{ml}$ syringe. The sterile solution was kept on ice until transfer to the infusion pump, and a sample of the infusate remaining at the end of infusion was analyzed by HPLC to establish that no conversion of $\gamma$-MBMTX to MTX had occurred chemically. Control experiments showed that HPLC would easily reveal the presence of as little as $0.1 \%$ MTX, but none was seen. Solutions of $\gamma$-MBMTX prepared as described above were stable in the refrigerator for up to $24 \mathrm{~h}$.

Analytical Procedures. Aliquots of serum and other fluids were assayed for total radioactivity by scintillation counting in 
5-10 $\mathrm{ml}$ Aquasol (New England Nuclear, Boston, MA, USA) in a Beckman Model LS335 instrument with a counting efficiency averaging $30 \%-35 \%$. Background counts determined from zero-time samples were subtracted from observed counts at each time point, and corrections were made for counting efficiency. Equivalent ${ }^{3} \mathrm{H}$ concentrations were then calculated on the basis of the measured specific activity of the particular batch of $\left[{ }^{3} \mathrm{H}\right]$ DBMTX or $\left[{ }^{3} \mathrm{H}\right] \gamma$-MBMTX used. Serum, urine, and CSF radioactivity could be measured adequately from $50-100 \mu \mathrm{l}$ aliquots, whereas bile contained so much radioactivity that a $1-\mu \mathrm{l}$ aliquot was sufficient.

For the determination of the relative proportions of $\left[{ }^{3} \mathrm{H}\right] \gamma$-MBMTX and $\left[{ }^{3} \mathrm{H}\right] \mathrm{MTX}$ in serum, freshly obtained samples were diluted to three times their volume with methanol and kept at $0^{\circ} \mathrm{C}$ overnight to coagulate the proteins. After centrifugation $\left(1,000 \mathrm{~g}, 4^{\circ} \mathrm{C}, 6 \mathrm{~min}\right), 100-\mu \mathrm{l}$ aliquots of supernatant were spotted on cellulose TLC sheets (Eastman 13181, with fluorescent indicator), overlaid with nonradioactive carriers, and developed with $0.05 M$ potassium phosphate, $\mathrm{pH}$ 7.4. Under these TLC conditions, DBMTX remained at the origin, whereas $\gamma$-MBMTX and MTX migrated with $R_{f}$ values of 0.6 and 0.8 , respectively. Appropriate zones were cut out and counted in $5 \mathrm{ml}$ Omnifluor (New England Nuclear, Boston, MA, USA). Samples were analyzed in triplicate and results were averaged. The standard deviation of the mean was generally $\pm 10 \%$. A similar procedure was followed for the analysis of urine, bile, and CSF samples, except that methanol addition was omitted.

In experiment involving nonradioactive $\gamma$-MBMTX and MTX, drug levels in serum and other fluids were determined by HPLC. Freshly obtained serum samples of at least $1 \mathrm{ml}$ were placed in Amicon CF-25 ultrafiltration cones (Amicon Corp., Beford, MA, USA), which were centrifuged at room temperature for $15 \mathrm{~min}$ in a bench-top clinical centrifuge. In some instances, filtrates were passed a second time through an Amicon UM2 ultrafiltration membrane with a 10,000 dalton cut-off. The filter disc was fitted into either a single cell Amicon Model 10-PA ultrafiltration apparatus of the propellent gas type or a 10-cell vacuum-operated device (Uni Pore Model 25, Bio-Rad Laboratories, Richmond, CA, USA). As an internal standard, 4-N,N-dimethylaminobenzoic acid was added to each filtered sample to give a final concentration of $4 \times 10^{-5} . M$. HPLC analysis was performed on a Waters instrument (Model ALC202) equipped with a U6K injector, Model 6000A pump, and Model 440 UV detector set for absorption at $280 \mathrm{~nm}$. Samples were injected onto a $3.9 \mathrm{~mm}$ ID $\times 30 \mathrm{~cm} \mu$ Bondapak CN column (Waters Associates, Milford, MA, USA). The eluent was made by mixing $1.16 \mathrm{~g}$ ammonium acetate, $4.0 \mathrm{~g} 40 \%$ aqueous tetrabutylammonium hydroxide (Aldrich Chemical Co., Milwaukee, WI), and $0.55 \mathrm{ml} 0.5 \mathrm{M}$ aqueous hexadecyltrimethylammonium chloride (Eastman Organic Chemicals, Rochester, NY, USA) in $1,000 \mathrm{ml}$ deionized water. The $\mathrm{pH}$ was adjusted to 7.8 with glacial acetic acid, and absolute ethanol was added to a final concentration of $20 \%$. Because of day-to-day variations in column performance, the amount of ethanol and ion-pairing reagents required occasional adjustment. Optimal separations and peak shapes were generally obtained when the ethanol content was $18 \%-23 \%$ and the flow rate was $1.1-1.3 \mathrm{ml} / \mathrm{min}$. The concentrations of $\gamma$-MBMTX and MTX in each sample were obtained by measuring peak heights relative to the internal standard, and referring to a linear calibration curve of peak height versus concentration [1]. The correlation coefficients for the calibration data, as determined from a least-squares regression equation of the form $y=m x+b$, was $>$ $99 \%$.

As a measure of the extent of binding of $\gamma$-MBMTX and MTX to proteins in monkey serum, randomly selected serum samples were divided in half. One portion was ultrafiltered for HPLC analysis as described above, while the other was diluted to three times its volume with methanol to denature the proteins and extract bound drugs. In control experiments, HPLC analysis of serum samples containing known amounts of $\gamma$-MBMTX and MTX treated in this way indicated $>90 \%$ recovery. The approximate extent of protein binding was calculated from the formula:

$$
\% \text { Binding }=\left[1-\frac{\text { Ultrafiltered drug }(\mu M)}{M \text { MeOH-extracted drug }(\mu M)}\right] \times 100 .
$$

\section{Results}

\section{Relative Proportions of Radioactive Products in Serum and Other Fluids}

The distribution of radiolabel in the serum, urine, and bile of Rhesus monkeys after IV bolus injection of $\left[{ }^{3} \mathrm{H}\right] \mathrm{DBMTX}$ is summarized in Table 1. Bioconversion of DBMTX to other products was very rapid. After $5 \mathrm{~min}$, no $\left[{ }^{3} \mathrm{H}\right] \mathrm{DBMTX}$ remained in the serum. Of the total radioactivity, 59\% co-migrated with $\gamma$-MBMTX (and $\alpha$-MBMTX which cannot be separated from the $\gamma$-isomer by TLC), a small fraction co-migrated with MTX, and a substantial amount (34\%) corresponded to other products. Over $60 \mathrm{~min}$, the relative proportion of monoester in the mixture declined to $224 \%$, while radioactivity corresponding to products other than monoester or MTX increased to $73 \%$. The distribution of radioactivity in the urine and bile was qualitatively similar to that in serum.

In contrast to the results obtained with the diester, TLC analysis of the serum after an IV bolus of $\left[{ }^{3} \mathrm{H}\right] \gamma$-MBMTX (Table 2) revealed the monoester to be clearly dominant $(67 \%-94 \%)$ for up to $60 \mathrm{~min}$, with lesser amounts of $\left[{ }^{3} \mathrm{H}\right] \mathrm{MTX}$ and only traces of other radioactive products. At $2 \mathrm{~h}$ the serum contained approximately equal proportions of $\gamma$-MBMTX and MTX, while other products continued to be barely discernible. Unchanged monoester was likewise the major species in urine over $60 \mathrm{~min}$ and for up to $4 \mathrm{~h}$ (Table 2), but its percentage of the total decreased gradually from $95 \%$ to $54 \%$ as the relative amount of MTX and other products increased from negligible levels to $31 \%$ and $15 \%$ respectively.

\section{$\gamma$-MBMTX and MTX Levels in Serum and CSF by HPLC Analysis}

As indicated in Table 3, a $10 \mathrm{~g} / \mathrm{m}^{2}$ dose of $\gamma$-MBMTX infused IV over $1.25 \mathrm{~h}$ (expt 4) resulted in $\gamma$-MBMTX and MTX levels in the serum and CSF that were well within the sensitivity range of HPLC analysis. At the end of the infusion the serum level of free (i.e., not protein-bound) $\gamma$-MBMTX reached $10^{-4}$ $M$, before declining fairly rapidly to $7 \times 10^{-6} M$ over the next $5 \mathrm{~h}$. During the same time, the $\gamma$-MBMTX concentration in CSF peaked at $1.5 \times 10^{-5} \mathrm{M}$, but declined more slowly, as evidenced by the change in calculated $\mathrm{CSF} / \mathrm{serum}$ ratio from 0.15 at $2 \mathrm{~h}$ to 1.0 at $5 \mathrm{~h}$ post-infusion. Over this period, free (not protein-bound) MTX in serum ranged from $10^{-5} M$ to $4.8 \times 10^{-6} \mathrm{M}$, and MTX levels in the CSF ranged from $4.7 \times$ $10^{-6}$ to $7.5 \times 10^{-6} \mathrm{M}$. Although they varied somewhat irregularly over time, CSF/serum ratios calculated from these data remained consistently in excess of 0.5 . Detectable 
Table 1. TLC analysis of the serum, urine, and bile of Rhesus monkeys following an IV dose of $\left[{ }^{3}\right.$ H]DBMTX

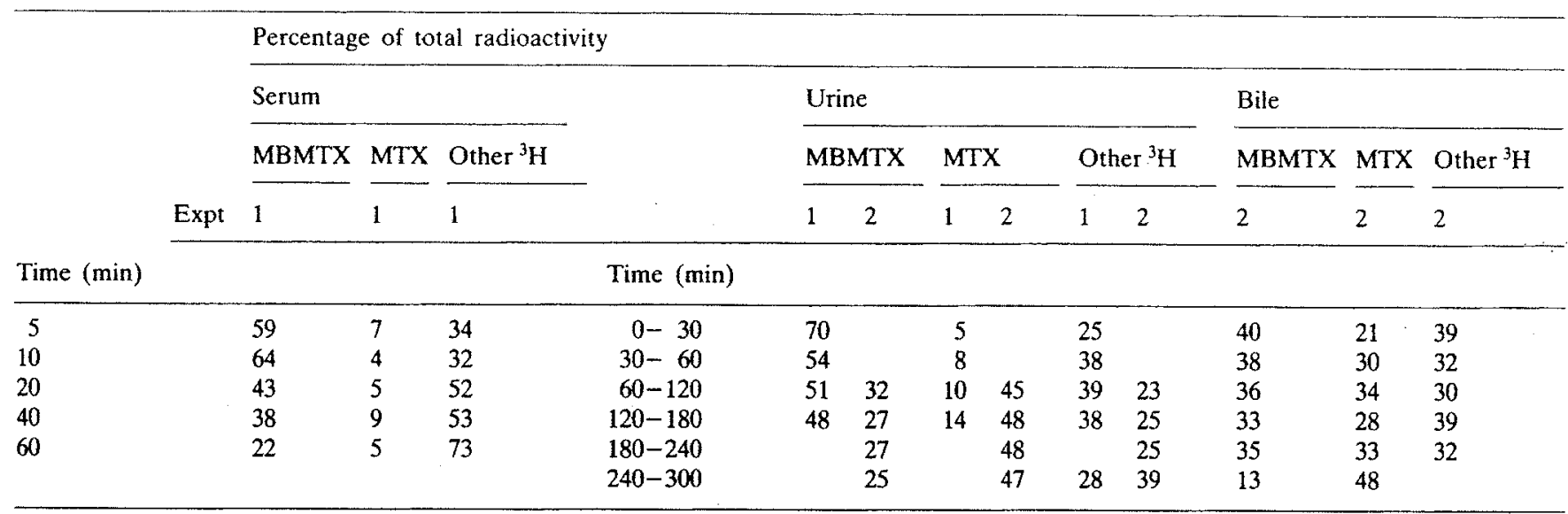

Experiment 1: $12.0 \mathrm{~kg}$ male Rhesus monkey, $29 \mathrm{mg}\left[{ }^{3} \mathrm{H}\right] \mathrm{DBMTX}$ (sp. act. $10 \mathrm{mCi} / \mathrm{mmol}$ ) given in $1.4 \mathrm{ml} \mathrm{dimethylsulfoxide} \mathrm{over} 1-2 \mathrm{~min}$. Experiment 2: $10.9 \mathrm{~kg}$ male Rhesus monkey, $23 \mathrm{mg}\left[{ }^{3} \mathrm{H}\right] \mathrm{DBMTX}$ (sp. act. $20 \mathrm{mCi} / \mathrm{mmol}$ ) given in $2.0 \mathrm{ml}$ dimethylsulfoxide over $2 \mathrm{~min}$. The animal in experiment 2 had a surgically implanted biliary diversion tube. MBMTX, mixture of $\alpha$-and $\gamma$-monobutyl esters, with the $\gamma$-isomer $(\gamma$-MBMTX) predominant by a $6: 1$ ratio (approx.) by HPLC (data not shown)

Table 2. TLC analysis of the serum and urine of a Rhesus monkey following an IV dose of $\left[{ }^{3} \mathrm{H}\right] \gamma$-MBMTX

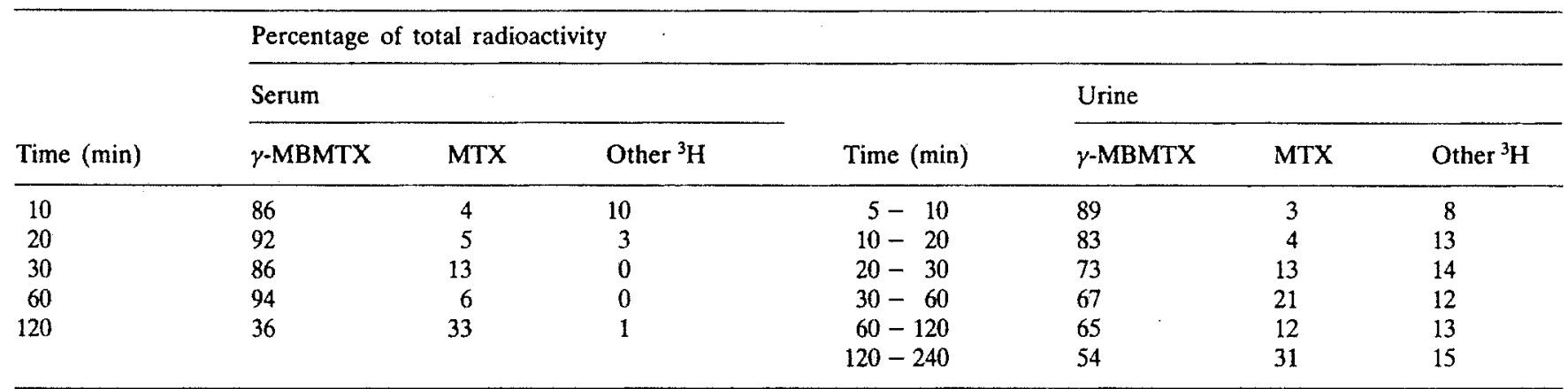

Experiment 3: $10.0 \mathrm{~kg}$ female Rhesus monkey, $27 \mathrm{mg}\left[{ }^{3} \mathrm{H}\right] \gamma$-MBMTX (sp. act. $16 \mathrm{mCi} / \mathrm{mol}$ ) given in $1.5 \mathrm{ml} 0.05 M$ Tris buffer, ph 8 , over $1-2 \min$

amounts of $\gamma$-MBMTX and MTX remained in the serum even after $24 \mathrm{~h}$, along with some MTX (approx. $4 \times 10^{-6} M$ ) in the CSF.

Serum and CSF levels in a monkey after a $1.25 \mathrm{~h}$ infusion of $10 \mathrm{~g} \mathrm{MTX} / \mathrm{m}^{2}$, as opposed to $\gamma$-MBMTX, are also presented (expt 5). The peak level of free MTX in serum at the end of infusion was approx. $2 \times 10^{-3} M$, but the concentration in the CSF, which peaked about $1 \mathrm{~h}$ later than in serum, reached a maximum that was 100 -fold lower $\left(2.3 \times 10^{-5} \mathrm{M}\right)$. The $\mathrm{CSF} /$ serum ratio ranged from 0.007 to 0.06 over the first $5.5 \mathrm{~h}$ post-infusion. By $24 \mathrm{~h}$ this ratio increased to 0.41 , reflecting the more rapid disappearance of MTX from serum than from CSF over this period.

Infusion of $10 \mathrm{~g} / \mathrm{m}^{2}$ of $\gamma$-MBMTX over $4 \mathrm{~h}$ (expt 6) led to results that were roughly comparable to those obtained after a $1.25 \mathrm{~h}$ infusion. Concentrations of unchanged $\gamma$-MBMTX in the serum and CSF at $0.4 \mathrm{~h}$ post-infusion were about $50 \%$ lower than in the earlier experiment, with similar decreases at other time points. The CSF/serum ratio exhibited a similar pattern of change over time, increasing from 0.18 at $4 \mathrm{~h}$ to 1.2 at $3 \mathrm{~h}$ post-infusion. However, on the following day the concentration of free $\gamma$-MBMTX dropped below $10^{-6} M$ in serum while remaining above $4 \times 10^{-6} M$ in CSF. The relatively lower $\gamma$-MBMTX level observed in serum after the longer infusion was accompanied by an increase in free MTX to a maximum of $5.4 \times 10^{-4} M$ at $2 \mathrm{~h}$. In contrast, while MTX could be measured for up to $24 \mathrm{~h}$ in the CSF of the monkey receiving the 1.25 - $h$ infusion, it could not be detected $\left(<10^{-6}\right.$ $M$ ) in the animal infused over $4 \mathrm{~h}$. Thus, CSF/serum ratios for MTX could not be calculated in this instance, though they must have been $<0.1$.

Also shown in Table 3 (expt 7) are the results of a second $\gamma$-MBMTX infusion in a monkey that had previously received $10 \mathrm{~g} \gamma-\mathrm{MBMTX} / \mathrm{m}^{2}$ over $1.25 \mathrm{~h}$. This earlier treatment was followed as usual by leucovorin rescue and the animal showed no overt signs of physiological impairment. Three months had elapsed between the first and second treatment, and serum creatinine, liver function tests, and peripheral blood counts were all in the normal range. Serum concentrations of unchanged $\gamma$-MBMTX (free drug) in this experiment reached a peak value of $2.8 \times 10^{-4} M$ at $0.2 \mathrm{~h}$ post-infusion, and remained above $10^{-4} M$ even at $3 \mathrm{~h}$, with proportionately elevated values being observed in the CSF. The $\gamma$-MBMTX level in serum dropped to $1.3 \times 10^{-5} M$ by $21 \mathrm{~h}$, but remained at $4 \times 10^{-5} M$ in the CSF, thus giving a calculated CSF/serum ratio of 3.1. The $\mathrm{CSF} / \mathrm{serum}$ ratios were still comparable, however, to those in the other $\gamma$-MBMTX infusions. MTX concentrations were elevated in both serum and CSF for up to $3 \mathrm{~h}$ in this experiment, but by the next day could be detected only in the CSF. 
Table 3. HPLC analysis of the serum and CSF of Rhesus monkeys following high-dose IV infusion of $\gamma$-MBMTX and MTX

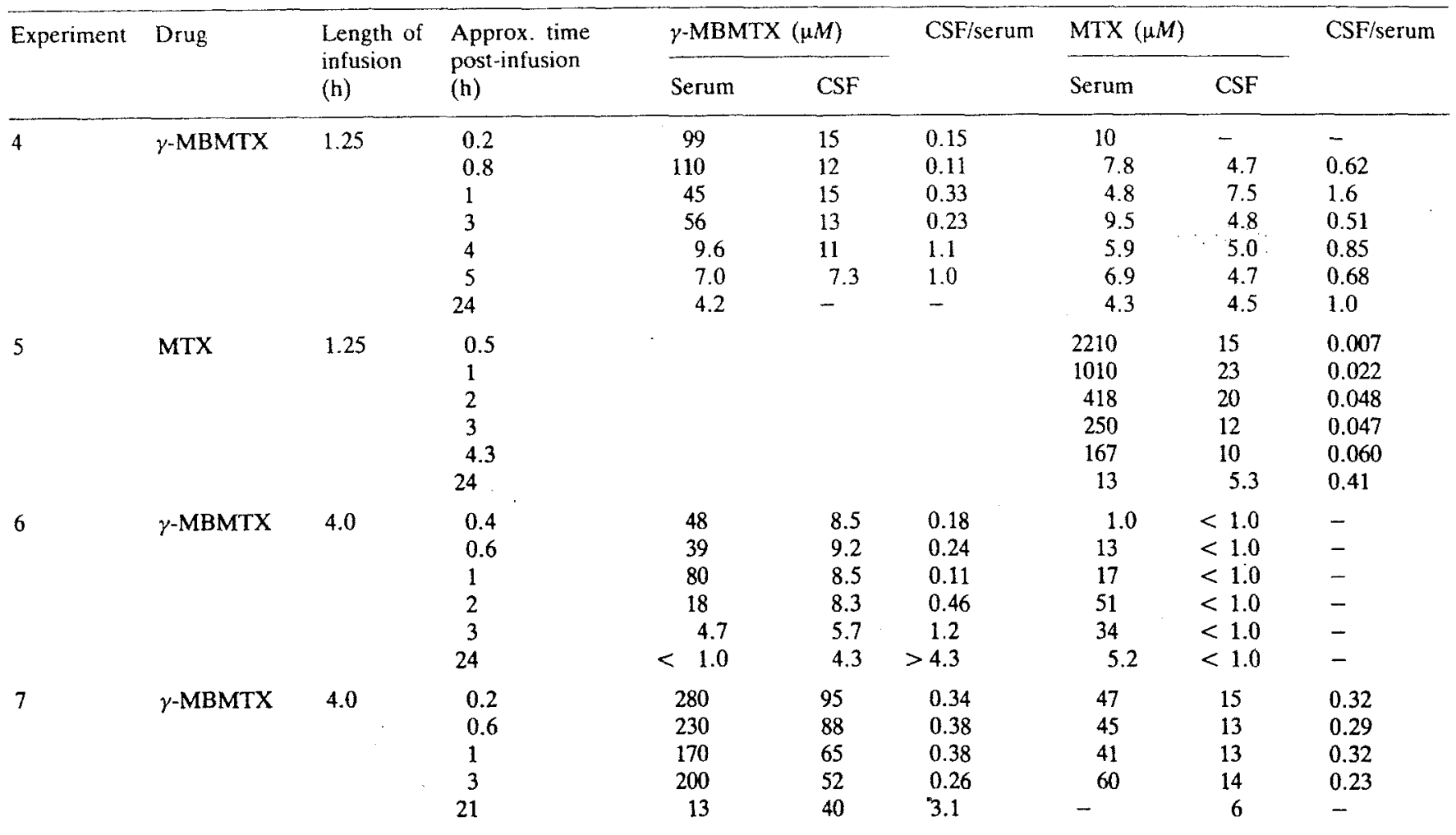

Experiments 4 and 7 were performed with the same female Rhesus monkey, weighing $5.5 \mathrm{~kg}$; experiments 5 and 6 were carried out with a different female, weighing $7.2 \mathrm{~kg}$. When the same animal was treated more than once, at least 3 months were allowed to elapse between doses, and serum creatinine, liver function tests, and peripheral blood counts were established to be within normal limits prior to treatment. The dose in all four experiments was $10 \mathrm{~g} / \mathrm{m}^{2}$, or approximately $600 \mathrm{mg} / \mathrm{kg}$. In each case, leucovorin rescue was begun at $24 \mathrm{~h}$, with calcium leucovorin $150 \mathrm{mg} / \mathrm{kg}$ being given daily in divided doses for at least 4 days. The second dose of $\gamma$-MBMTX given to the monkey in experiment 7 was not tolerated, and the animal died after a few days despite leucovorin rescue. Death was ascribed to acute renal failure, and there was histopathological evidence of extensive drug deposition in the proximal renal tubules. The peak level of $\gamma$-MBMTX (free drug) in this experiment, calculated by correcting for serum protein protein binding as discussed in the text, was probably $>10 \mathrm{~m} M$, and it should be noted that although fluids were administered for several hours post-infusion, the urinary output was markedly lower in this experiment than in the others

Table 4. Estimation of the extent of binding of MTX and $\gamma$-MBMTX to serum proteins in the Rhesus monkey by HPLC analysis

\begin{tabular}{|c|c|c|c|c|c|}
\hline \multicolumn{2}{|c|}{ MTX $(\mu M)$} & \multirow{2}{*}{$\begin{array}{l}\text { Extent of } \\
\text { binding } \\
(\%)^{\mathrm{a}}\end{array}$} & \multicolumn{2}{|c|}{$\gamma$-MBMTX $(\mu M)$} & \multirow{2}{*}{$\begin{array}{l}\text { Extent of } \\
\text { binding } \\
(\%)^{\mathrm{a}}\end{array}$} \\
\hline $\begin{array}{l}\mathrm{MeOH} \\
\text { Extrac- } \\
\text { tion }\end{array}$ & $\begin{array}{l}\text { Uitra- } \\
\text { filtra- } \\
\text { tion }\end{array}$ & & $\begin{array}{l}\mathrm{MeOH} \\
\text { Extra- } \\
\text { tion }\end{array}$ & $\begin{array}{l}\text { Ultra } \\
\text { filtra- } \\
\text { tion }\end{array}$ & \\
\hline 3.4 & 1.7 & 50 & 74 & 2.0 & $>99$ \\
\hline 4.8 & 3.1 & 35 & 130 & 2.6 & $>99$ \\
\hline 5.5 & 3.9 & 29 & 290 & 2.5 & $>99$ \\
\hline 6.4 & 5.3 & 17 & & & \\
\hline
\end{tabular}

Calculated from the formula:

Extent of binding $(\%)=\left[1-\frac{\text { Ultrafiltered drug }(\mu M)}{\text { MeOH-extracted drug }(\mu M)}\right] \times 100$; see also Methods

\section{Binding of $\gamma-M B M T X$ and $M T X$ to Serum Proteins}

When the serum concentration of $\gamma$-MBMTX and MTX was compared in samples processed in parallel by ultrafiltration and $\mathrm{MeOH}$ precipitation (Table 4), it was evident that the two compounds possess markedly different affinities for serum proteins. The fraction of MTX that was protein-bound appeared to depend somewhat on the total (i.e., methanol-extractable) concentration of drug, and ranged from $17 \%$ at 6.4 $\mu M$ to $50 \%$ at $3.4 \mu M$. In contrast, the fraction of $\gamma$-MBMTX that remained protein-bound by these measurements was $>99 \%$ and this value did not vary over a range of total concentration from 74 to $290 \mu M$.

\section{Discussion}

Information on the pharmacokinetics and metabolic fate of MTX in Rhesus monkeys is available from several studies [3, $11,12,15,16,19]$. Disappearance of total radioactivity from plasma after a bolus IV dose of $\left[{ }^{3} \mathrm{H}\right] \mathrm{MTX}$ is rapid and obeys biexponential kinetics [3]. Radioactivity declines to less than $3 \%$ of the administered dose within a few minutes, with clearance occurring predominantly via renal as opposed to hepatobiliary excretion [11]. We have observed a similar pattern of biexponential disappearance of total radioactivity from the serum of monkeys treated with [ $\left.{ }^{3} \mathrm{H}\right] \mathrm{DBMTX}$ or $\left[{ }^{3} \mathrm{H}\right] \gamma$-MBMTX, though it should be noted that measurements of total radioactivity are of little significance unless one knows the nature of the radioactive species present at each time point [16]. A considerable fraction of the total radioactivity in serum after an IV dose of $\left[{ }^{3} \mathrm{H}\right] \mathrm{DBMTX}$ consists of products other than $\gamma$-MBMTX or MTX, and the relative proportion of these 
unidentified materials increases gradually over a 1 -h period. In contrast, very little of the total serum radioactivity after an IV bolus of $\left[{ }^{3} \mathrm{H}\right] \gamma$-MBMTX consists of products other than $\left[{ }^{3} \mathrm{H}\right] \mathrm{MTX}$ and unchanged monoester, and the latter actually comprises by far the major fraction over the same 1-h time span (Table 2). This marked difference in metabolic fate between the diester and monoester suggests that the promising in vitro effects observed with this compound may be exploitable in vivo. Similar results would be expected for other MTX ester of primary alcohols.

The large amounts of DBMTX metabolites in bile point to the liver as the major site of DBMTX metabolism. This is not surprising for a lipid-soluble molecule such as DBMTX, and is reminiscent of the high degree of hepatic extraction reported for $3^{\prime}, 5^{\prime}$-dichloromethotrexate [9]. The likely importance of hepatobiliary processing in the pharmacology of DBMTX is indicated also by the larger fraction of total administered radioactivity that can be recovered in bile as compared with urine. Henderson and co-workers [11] reported the cumulative excretion of radioactivity in the bile of a cannulated Rhesus monkey $6 \mathrm{~h}$ after an IV bolus of $\left[{ }^{3} \mathrm{H}\right] \mathrm{MTX}$ to be only $5 \%$ of the total administered dose, as compared with $44 \%$ in the urine. At $24 \mathrm{~h}$ these values had increased to $16 \%$ and $73 \%$, respectively, but the ratio was still heavily in favor of renal over biliary excretion. In the present study, total radioactivity in the bile of the monkey with a cannula $5 \mathrm{~h}$ after an IV bolus of [ ${ }^{3}$ H]DBMTX (Table 1, expt 2 ) was $32 \%$ of the administered dose, whereas the amount recovered in urine over the same period amounted to only $20 \%$ of the administered dose (data not shown). Since about $50 \%$ of the injected label in this experiment is not accounted for, we assume that it is retained in the tissues or else is in the stools, which were not collected for analysis. Analysis of tissue-bound radioactivity would have necessitated sacrificing the animal, which we did not wish to do at the time. It should be noted that in their in vitro studies, Johns and co-workers [14] observed lipid-soluble diesters of MTX to be excellent substrates for hepatic aldehyde oxidase, which detoxifies MTX by 7-hydroxylation [9, 11, 12, 15, 31]. Since 7-hydroxymethotrexate is present in substantial amount in monkey serum and urine after MTX treatment $[12$; unpublished results from this laboratory], some of the hepatobiliary products after DBMTX administration may consist of 7-hydroxy derivatives.

Since $\gamma$-MBMTX is relatively stable toward metabolism in primates and also is nearly equipotent with MTX against dihydrofolate reductase in vitro, a critical question is whether it possesses an improved ability to penetrate the CSF. According to Poplack and co-workers [19], continuous MTX infusion at a rate adjusted to give a steady-state serum level of $10^{-5} M$ gives a CSF/serum ratio of only $0.01-0.04$, which is consistent with the known low permeability of the blood-brain barrier toward MTX [27, 28]. Similarly, from data of Kimelberg and co-workers [15, 16] for serum and CSF total radioactivity following an IV bolus of $\left[{ }^{3} \mathrm{H}\right] \mathrm{MTX}$, the CSF/serum ratio at $1 \mathrm{~h}$ and thereafter can be estimated to be $0.02-0.03$. Measurements of total radioactivity, however, are complicated by the fact that substantial amounts of $\left[{ }^{3} \mathrm{H}\right] \mathrm{H}_{2} \mathrm{O}$ arise in vivo when $\left[{ }^{3} \mathrm{H}\right] \mathrm{MTX}$ is given $[4,5]$. Once formed, $\left[{ }^{3} \mathrm{H}\right] \mathrm{H}_{2} \mathrm{O}$ can freely penetrate the CSF and also exchange with a host of endogenous species that can contribute to total CSF radioactivity. On the basis of these considerations we elected to measure drug levels in the serum and CSF directly by HPLC, using nonradioactive material. Enzymatic assays, which would be more sensitive, were excluded since they would not discriminate between $\gamma$-MBMTX and MTX, which have comparable binding affinities toward dihydrofolate reductase [24]. A high dose $\left(10 \mathrm{~g} / \mathrm{m}^{2}\right)$ was chosen to ensure that HPLC-detectable levels of $\gamma$-MBMTX and MTX would be present over several hours not only in serum, but also in the CSF. The results (Table 3 ) indicate faster elimination of the ester from the serum than from the CSF. This is due, in part, to some cleavage to MTX by serum esterases, as evidenced by the almost immediate detection of small amounts of MTX after injection of $\gamma$-MBMTX. The MTX concentration remains fairly constant over several hours, and may actually exceed that of the ester as the latter is eliminated. Slower disappearance of the ester from CSF than from serum is consistent with its lipophilicity, which would be expected to promote binding to lipid-rich sites in the brain and spinal cord.

It is of interest to note that the peak concentration of free drug (not protein-bound) in serum after $\gamma$-MBMTX infusion was about 20 times lower than that of MTX after a comparable MTX infusion (expts 4 and 5) even though levels of the two drugs in the CSF were almost the same. The approximately 10 -fold more favorable CSF/serum ratio for $\gamma$-MBMTX than for MTX is therefore not due to an inherently greater ability to penetrate the CSF, but reflects instead a 10 -fold difference in free drug level in the systemic circulation. The lower free drug level in serum in the case of the ester appears to be due to tenacious binding to serum proteins. From the data in Table 4, we estimate that observed $\gamma$-MBMTX levels in serum after ultrafiltration represent only $0.5 \%-2.0 \%$ of the total drug, whereas observed levels of MTX measured in the same way are closer to $50 \%$ of the total amount present. After appropriate correction for total drug in serum, the peak value for both drugs is the same, approx. $5 \times 10^{-3} M$. After $24 \mathrm{~h}$, on the other hand, total $\gamma$-MBMTX and total MTX levels are calculated to be approx. $2 \times 10^{-4}$ and $2 \times 10^{-5} \mathrm{M}$, respectively. If total as opposed to free drug levels are compared, therefore, it appears that $\gamma$-MBMTX and MTX attain about the same peak levels at the end of infusion, but that after $24 \mathrm{~h}$, higher total concentrations in the blood are obtained with $\gamma$-MBMTX than with MTX. This suggests that $\gamma$-MBMTX might have a somewhat more prolonged therapeutic effect than MTX when given on the same short-infusion schedule.

In summary, we conclude that (1) esterification of MTX appears to promote hepatobiliary processing relative to direct renal excretion; (2) $\gamma$-MBMTX is formed rapidly from DBMTX in vivo, but subsequent hydrolysis to MTX by esterases is relatively slow in the monkey, with unchanged monoester being detectable for up to $24 \mathrm{~h}$; (3) fewer metabolic products are formed from $\gamma$-MBMTX than from DBMTX, possibly reflecting decreased hepatic extraction; and (4) administration of $\gamma$-MBMTX results in CSF levels comparable to those at the same dose rate of MTX, but because of a large difference in affinity for serum proteins, the concentration of free monoester in serum is decreased $>10$-fold relative to MTX. In conjunction with our earlier finding that DBMTX and $\gamma$-MBMTX are as active against MTX-resistant cells with a transport defect as they are against the MTX-sensitive parent line [25], the results of this study provide support for continued work on esters and other lipophilic side-chain derivatives of MTX as potential agents for the therapy of MTX-resistant tumors.

Acknowledgements. The capable technical assistance of Susan Easter, Michael Egan, Nick Papathanasopoulos, and Dorothy Trites is gratefully acknowledged. Thanks are likewise due to Dr Robert 
B. Angier for providing the $\gamma$-MBMTX used in the high-dose experiments, and to Dr Emil Frei III for his continuing interest in this project.

This research was supported in part by grants CA 25394, CA 19589, CA 18662, CA 00075 (to H.T.A.), and CA 06516 from the National Cancer Institute, National Institutes of Health.

\section{References}

1. Abelson HT, Ensminger WD, Kufe D, Rosowsky A, Uren JR (1979) High-dose methotrexate-carboxypeptidase $G_{1}-$ A selective approach to the therapy of central nervous system tumors. In: Kisliuk RL, Brown GM (eds) Chemistry and biology of pteridines. Elsevier/North Holland, New York, pp 629-633

2. Beardsley GP, Rosowsky A, McCaffrey RP, Abelson HT (1979) Methotrexate di-n-butyl ester effects on thymidine metabolism. Biochem Pharmacol 28: 3069

3. Bourke RS, Chheda G, Bremer A, Watanabe O, Tower DB (1975) Inhibition of renal tubular transport of methotrexate by probenecid. Cancer Res 35: 110

4. Calvert AH, Jarman M (1979) Radiolabelled methotrexate: a warning. Lancet: 166

5. Calvert AH, Bondy PK, Harrap KR (1976) Some observations on the human pharmacology of methotrexate. Cancer Treat Rep 61: 1647

6. Chaykovsky M, Rosowsky A, Modest EJ (1973) Side-chain altered methotrexate analogues designed for improved membrane transport. J Heterocycl Chem 10: 425

7. Chaykovsky M, Rosowsky A, Papathanasopoulos N, Chen KKN, Modest EJ, Kisliuk RL, Gaumont Y (1974) Methotrexate analogues. 3. Synthesis and biological properties of some side-chain altered analogues. J Med Chem 17:1212

8. Curt GA, Tobias JS, Kramer RA, Rosowsky A, Parker LM, Tattersall MHN (1976) Inhibition of nucleic acid synthesis by the di-n-butyl ester of methotrexate. Biochem Pharmacol 25: 1943

9. Davidson JD, Oliverio VT (1964) The physiologic disposition of dichloromethotrexate- $\mathrm{Cl}^{36}$ in man. Clin Pharmacol 16:321

10. Eisenfeld AJ, Mautner HG, Welch AD (1962) Comparative effects of amethopterin and its dimethyl ester on subcutaneous and intracerebral neoplasms. Proc Am Assoc Cancer Res 3: 316

11. Henderson ES, Adamson RH, Denham C, Oliverio VT (1965) The metabolic fate of tritiated methotrexate. I. Absorption, excretion, and distribution in mice, rats, dogs, and monkeys. Cancer Res 25: 1008

12. Jacobs SA, Stoller RG, Chabner BA, Johns DG (1977) Dose-dependent metabolism of methotrexate in man and Rhesus monkeys. Cancer Treat Rep 61:651

13. Johns DG, Farquhar D, Chabner BA, Wolpert MK, Adamson RH (1973a) Antineoplastic activity of lipid-soluble dialkyl esters of methotrexate. Experientia 29: 1104

14. Johns DG, Farquhar D, Wolpert MK, Chabner BA, Loo TL (1973b) Dialkyl esters of methotrexate and 3',5'-dichloromethotrexate: synthesis and interaction with aldehyde oxidase and dihydrofolate reductase. Drug Metab Dispos 1:580

15. Kimelberg HK, Tracy TF, Biddlecome SF, Bourke RS (1976) The effect of entrapment in liposomes on the in vivo distribution of $\left[{ }^{3} \mathrm{H}\right]$ methotrexate in a primate. Cancer Res $36: 2649$

16. Kimelberg HK, Biddlecome SM, Bourke RS (1977) Distribution and degradation of $\left[{ }^{3} \mathrm{H}\right]$ methotrexate after intravenous and cerebral intraventricular injection in primates. Cancer Res 37: 157
17. McCullough, JL, Snyder DS, Weinstein GD, Friedland A, Stein B (1976) Factors affecting human percutaneous penetration of methotrexate and its analogues in vitro. J Invest Dermatol 66: 103

18. Piper JR, Montgomery JA, Sirotnak FM, Chello PL (1982) Synthesis of $\alpha$-and $\gamma$-substituted amides, peptides, and esters of methotrexate and their evaluation as inhibitors of folate metabolism, J Med Chem 25:182

19. Poplack DG, Bleyer WA, Wood HJ, Kostolick M, Savitch JL, Ommaya AK (1977) A primate model for the study of methotrexate pharmacokinetics in the central nervous system. Cancer Res 37: 1982

20. Rosowsky A (1973) Methotrexate analogues. 2. A facile method of preparation of lipophilic derivatives of methotrexate and $3^{\prime}, 5^{\prime}$-dichloromethotrexate by direct esterification. $J$ Med Chem $16: 1190$

21. Rosowsky A, Yu CS (1978) Methotrexate analogues. 10. Direct coupling of methotrexate and diethyl L-glutamate in the presence of peptide bond-forming reagents. J Med Chem 21:170

22. Rosowsky A, Yu CS (1979) New methods of neutral esterification of methotrexate and related compounds. In: Kisliuk RL, Brown GM (eds) Chemistry and biology of pteridines. Elsevier/North Holland, New York, pp 273-277

23. Rosowsky A, Ensminger WD, Lazarus H, Yu CS (1977) Methotrexate analogues. 8. Synthesis and biological evaluation of bisamide derivatives as potential prodrugs. J Med Chem 20: 925

24. Rosowsky A, Beardsley GP, Ensminger WD, Lazarus H, Yu CS (1978) Methotrexate analogues. 11. Unambiguous chemical synthesis and in vitro biological evaluation of $\alpha$ - and $\gamma$-monoesters as potential prodrugs. J Med Chem 21:380

25. Rosowsky A, Lazarus H, Yuan GC, Beltz WR, Mangini L, Abelson HT, Modest EJ, Frei E III (1980) Effects of methotrexate esters and other lipophilic antifolates on methotrexate-resistant human leukemic lymphoblasts. Biochem Pharmacol 29:648

26. Rosowsky A, Forsch R, Uren J, Wick M (1981) Methotrexate analogues. 14. Synthesis of new $\gamma$-substituted derivatives as dihydrofolate reductase inhibitors and potential anticancer agents. J Med Chem 24: 1450

27. Rubin R, Owens E, Rall DP (1968) Transport of methotrexate by the choroid plexus. Cancer Res 28:689

28. Shapiro WR, Ansman JI, Rall DP (1970) Studies on the chemotherapy of experimental brain tumors: evaluation of 1,3-bis(2-chloroethyl)-1-nitrosourea, cyclophosphamide, mithramycin, and methotrexate. Cancer Res 30:2401

29. Szeto DW, Cheng YC, Rosowsky A, Yu CS, Modest EJ, Piper JR, Temple C Jr, Elliott RD, Rose JD, Montgomery JA (1979) Human thymidylate synthetase. III. Structure-activity relationships. Biochem Pharmacol 28: 2633

30. Warren JD, Angier RB, Morton G, Rosowsky A (1980) A preparative scale synthesis and chromatographic separation of methotrexate $\alpha$ - and $\gamma$-monobutyl esters. Org Prep Proc Intern 12: 191-197

31. Watson E, Cohen JL, Chan KK (1978) High-pressure liquid chromatographic determination of methotrexate and its major metabolite, 7-hydroxymethotrexate, in human plasma. Cancer Treat Rep 62: 381

32. Weinstein GD, McCullough JL (1975) Effects of methotrexate esters on normal and psoriatic skin. Arch Dermatol 111:471

Received April 20 